\title{
Metabolic effects of orally administered small-molecule agonists of GPR55 and GPR119 in multiple low-dose streptozotocin-induced diabetic and incretin-receptor-knockout mice
}

\author{
Aine M. McKillop ${ }^{1}$ • Brian M. Moran ${ }^{1}$ - Yasser H. A. Abdel-Wahab ${ }^{1}$. \\ Noella M. Gormley ${ }^{1}$ - Peter R. Flatt ${ }^{1}$
}

Received: 2 June 2016 / Accepted: 19 August 2016 /Published online: 27 September 2016

(C) The Author(s) 2016. This article is published with open access at Springerlink.com

\begin{abstract}
Aims/hypothesis Abnormal cannabidiol (Abn-CBD) and AS-1269574 are potent selective agonists for GPR55 and GPR119, respectively. The present study evaluated the actions and ability of these small-molecule agonists to counteract experimental diabetes in mice.

Methods Diabetes was induced in NIH Swiss mice by five consecutive daily intraperitoneal injections of $40 \mathrm{mg} /(\mathrm{kg}$ body weight) streptozotocin. Diabetic mice received daily oral administration of Abn-CBD or AS-1269574 (0.1 $\mu \mathrm{mol} / \mathrm{kg})$ or saline vehicle $(0.9 \% \mathrm{wt} / \mathrm{vol} . \mathrm{NaCl})$ over 28 days. Body weight, food intake, fluid intake, plasma glucose, insulin, glucose tolerance, insulin release, lipid profile and pancreatic morphology were examined. Mechanism of action of agonists was assessed in acute studies using incretin-receptor-knockout mice.

Results Abn-CBD and AS-1269574 decreased plasma glucose $(20-26 \%, p<0.05)$ and increased circulating insulin $(47-48 \%, p<0.05)$ by $10-28$ days, compared with saline-treated diabetic controls. Food intake and polydipsia were reduced by both agonists $(21-23 \%, p<0.05$ and $33-35 \%, p<0.01$, respectively). After 28 days of treatment, plasma glucagon concentrations were reduced $(p<0.01)$ and glucose tolerance was enhanced by $19-44 \%$ by
\end{abstract}

Electronic supplementary material The online version of this article (doi:10.1007/s00125-016-4108-z) contains peer-reviewed but unedited supplementary material, which is available to authorised users.

Aine M. McKillop

am.mckillop@ulster.ac.uk

1 School of Biomedical Sciences, Ulster University, Cromore Road, Coleraine BT52 1SA, Northern Ireland, UK
Abn-CBD $(p<0.05$ or $p<0.001)$ and AS-1269574 $(p<0.05$ to $p<0.001)$. Plasma insulin responses were improved $(p<0.01)$ and insulin resistance was decreased $(p<0.05$ or $p<0.01)$ in both Abn-CBD- and AS-1269574treated groups. Triacylglycerols were decreased by $19 \%$ with Abn-CBD $(p<0.05)$ and 32\% with AS-1269574 $(p<0.01)$ while total cholesterol was reduced by $17 \%$ $(p<0.01)$ and 15\% $(p<0.05)$, respectively. Both agonists enhanced beta cell proliferation $(p<0.001)$ although islet area was unchanged. Acute studies in Gipr-and Glp1rknockout mice revealed an important role for the glucagon-like peptide 1 (GLP-1) receptor in the actions of both agonists, with the glucose-lowering effects of Abn-CBD also partly mediated through the glucosedependent insulinotropic peptide (GIP) receptor.

Conclusions/interpretation These data highlight the potential for fatty acid G-protein-coupled receptor-based therapies as novel insulinotropic and glucose-lowering agents acting partly through the activation of incretin receptors.

Keywords Beta cell regeneration - Diabetes · Fatty acid agonists · Glucose homeostasis · G-protein-coupled receptors $\cdot$ Insulin secretion $\cdot$ Multiple low-dose streptozotocin

$\begin{array}{ll}\text { Abbreviations } \\ \text { Abn-CBD } & \text { Abnormal cannabidiol } \\ \text { CB1 } & \text { Cannabinoid receptor 1 } \\ \text { CB2 } & \text { Cannabinoid receptor } 2 \\ \text { CBD } & \text { Cannabidiol } \\ \text { DEXA } & \text { Dual-energy x-ray absorption } \\ \text { DPP-IV } & \text { Dipeptidyl-peptidase-IV } \\ \text { GLP-1 } & \text { Glucagon-like peptide-1 } \\ \text { GIP } & \text { Glucose-dependent insulinotropic peptide }\end{array}$


GPCR G-protein coupled receptor

STZ Streptozotocin

\section{Introduction}

NEFAs play a complex role in glucose homeostasis and the pathogenesis of type 2 diabetes [1] and recent studies have shown that G-protein-coupled receptors (GPCRs) are involved in sensing NEFAs [2, 3]. NEFAs have an emerging role in improving glucose-stimulated insulin release from pancreatic beta cells and improving insulin sensitivity in liver and skeletal muscle [4]. GPCRs have different affinities for fatty acids of varying chain lengths. Thus whereas mediumand long-chain fatty acids activate GPR40 and GPR120, short-chain fatty acids are known to serve as ligands for GPR41 and GPR43 [4]. Furthermore, novel receptors GPR55 and GPR119 have recently been shown to affect blood glucose control, and activation of these receptors with novel synthetic fatty acids may have therapeutic potential for type 2 diabetes [5].

GPR119 has been identified on pancreatic beta cells and intestinal $\mathrm{L}$ cells and $\mathrm{K}$ cells and has the ability to enhance glucose-stimulated insulin release and the secretion of both glucagon-like peptide-1 (GLP-1) and glucose-dependent insulinotropic peptide (GIP) [6]. These incretin hormones have a variety of actions in pancreatic islets including enhancement of insulin biosynthesis and glucose-stimulated insulin release, stimulation of beta cell proliferation and inhibition of beta cell apoptosis [7]. GLP-1 additionally inhibits glucagon secretion [8]. GPR119 has been shown to bind a variety of lipid-derived ligands, as well as a range of small synthetic molecules. Several endogenous and synthetic GPR119 agonists have been shown to exhibit insulinsecretory properties in clonal beta cells, isolated islets and in vivo in mice $[9,10]$. AS-1269574 is a specific and potent fatty acid GPR119 agonist that enhances glucose-dependent insulin secretion $[9,10]$. AS-1269574 has also been implicated in GLP-1 secretion and increased proglucagon gene promoter activity via GPR119 in a mouse L cell line (GLUTag) [11]. A recent study found that a synthetic GPR119 agonist (PSN-632408) can enhance beta cell regeneration, improve islet cell graft survival and augment plasma active GLP-1 [12]. Previous reports have found that GPR119 agonists exhibit enhanced potency in vivo in combination with inhibition of enzymes such as fatty acid amide hydrolase inhibitor (URB-597) [13] or dipeptidyl-peptidase-IV (DPP-IV; sitagliptin) [14, 15].

GPR55 is expressed in the central nervous system, ileum, adipose tissue and endocrine pancreas, being predominantly on insulin-secreting beta cells [16, 17]. GPR55 was initially de-orphanised as a cannabinoid receptor and this receptor binds many cannabinoid compounds. However, some
GPR55 ligands are not cannabinoids and do not bind to either cannabinoid receptor 1 (CB1) or 2 (CB2) [16]. Cannabidiol (CBD) is a known GPR55 antagonist and has structural similarity to cannabinol and $\Delta^{9}$-tetrahydrocannabinol [18]. A range of synthetic $\mathrm{CBD}$ analogues have been synthesised, including abnormal cannabidiol (Abn-CBD), O-1918 and O-1602, which all act via GPR55 [5]. GPR55 has been associated with several physiological roles including anti-inflammatory activity [19], osteoclast function [20], insulin secretion and glucose homeostasis [17, 21, 22]. GPR55 agonists exhibited insulinotropic properties in clonal beta cells, isolated islets and in vivo in mice [17, 21, 22], with Abn-CBD noted as having the maximum potency and selectivity for GPR55 [21]. A recent study also using mice found that ablation of the GPR55 receptor increases adiposity and insulin resistance, selectively decreasing physical activity [23]. Further studies are required to assess the efficacy of Abn-CBD administration in the treatment of diabetes and other obesity-related diseases.

Recently we identified Abn-CBD and AS-1269574 as potent selective agonists for GPR55 and GPR119, respectively; both agonists exhibited acute glucose-lowering and insulinotropic properties in mice $[9,21]$. In the present study we have evaluated the long-term glucose-lowering effects of small-molecule agonists Abn-CBD and AS-1269574 in mice with diabetes induced by multiple-low-dose streptozotocin (STZ). To gain further information on the potential mechanism of action of these GPCR agonists, glucose-lowering and insulin-releasing properties were assessed in vivo using Gipr- and Glp1r-knockout mice.

\section{Methods}

See electronic supplementary material (ESM) Methods for details of materials.

Animals Male NIH Swiss mice (10-16 weeks old) were purchased from Harlan, UK. Gipr-and Glp1r-knockout mice crossed with the C57BL/6 strain (courtesy of B. Thorens, Lausanne, Switzerland and D. J. Drucker, Toronto, ON, Canada) and age-matched control wild-type C57BL/6 mice were obtained from an in-house breeding colony. The study was conducted in accordance with the Guide for the Care and Use of Laboratory Animals (2011) and the UK Animal (Scientific Procedures) Act 1986 and ARRIVE guidelines for reporting experiments involving animals [24].

Chronic administration of Abn-CBD and AS-1269574 in STZ-induced diabetic mice In a long-term study (28 days), the effects of daily oral administration of Abn-CBD and AS-1265974 (both at $0.1 \mu \mathrm{mol} /[\mathrm{kg}$ body weight]) [9, 21] or saline vehicle $(0.9 \% \mathrm{wt} / \mathrm{vol}$. $\mathrm{NaCl})$ were examined in 
multiple-low-dose streptozotocin-induced diabetic NIH Swiss mice. To induce diabetes, NIH Swiss mice fasted for $4 \mathrm{~h}$ received five consecutive daily intraperitoneal injections of STZ (40 mg/[kg body weight]). See ESM Methods for further details.

Acute in vivo effects of Abn-CBD and AS-1269574 in incretin-receptor-knockout mice Age-matched, non-fasted Gipr-knockout, Glp1r-knockout and wild-type C57/BL6 mice $(n=6)$ received an oral injection of glucose alone (18 $\mathrm{mmol} /[\mathrm{kg}$ body weight $]$ ) or in combination with either Abn-CBD or AS-1269574 (both at $0.1 \mu \mathrm{mol} /[\mathrm{kg}$ body weight]). See ESM Methods for further details.

Acute in vivo effects of Abn-CBD and AS-1269574 and relevant antagonists in lean mice Fasted male lean NIH Swiss mice received glucose $(18 \mathrm{mmol} /[\mathrm{kg}$ body weight] $)$
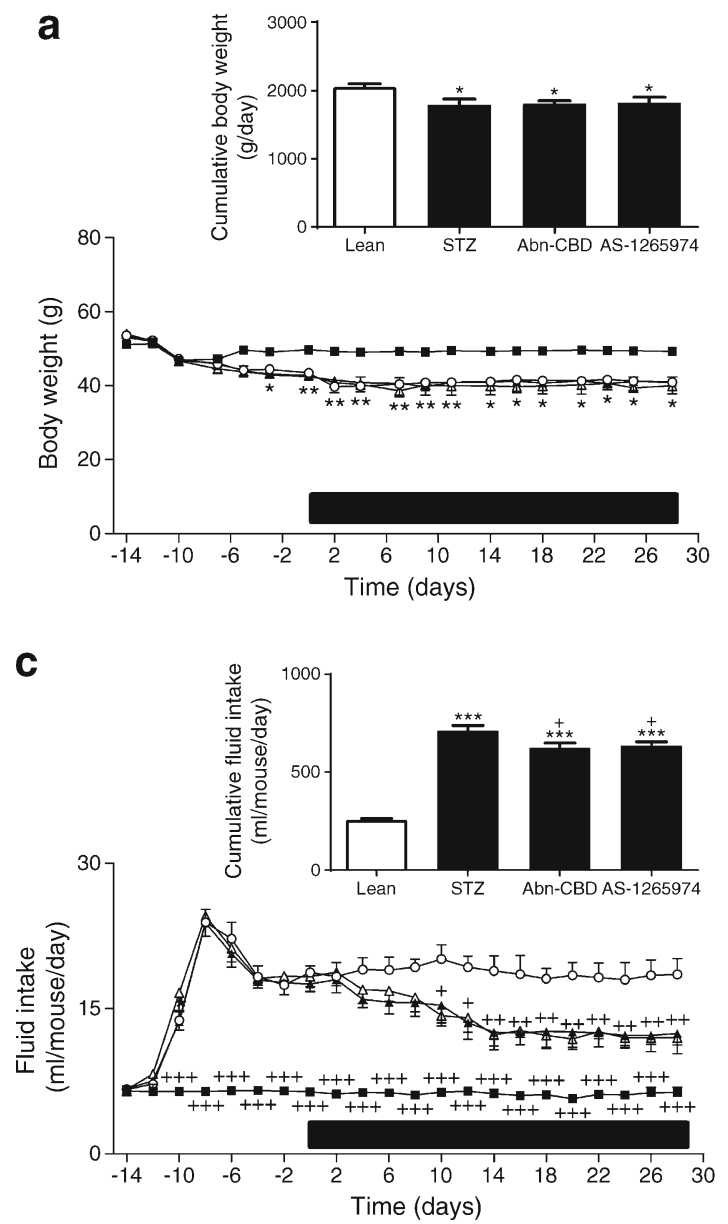

Fig. 1 Effect of daily administration of Abn-CBD and AS-1269574 on body weight (a), food intake (b), fluid intake (c) and plasma glucose (d) in STZ-induced diabetic mice. Variables were measured before and during 28 day treatment with Abn-CBD, AS-1269574 or saline vehicle (treatment period indicated by the horizontal black bar). Black squares, non-diabetic mice treated with saline (normal); white circles, STZ- alone or in combination with GPR119 agonist AS1269754 and GPR119 antagonist exendin (9-39) $(0.1 \mu \mathrm{mol} /[\mathrm{kg}$ body weight]) or GPR55 agonist Abn-CBD and GPR55 antagonist CBD orally or intraperitoneally and glucose/insulin was measured.

Histology Pancreatic tissues were removed at 28 days and processed as previously reported [21]. See ESM Methods for further details.

Biochemical analysis Analysis of blood samples was undertaken as previously reported [21, 25]. See ESM Methods for further details.

Statistics Data are expressed as the means \pm SEM. Results were compared using the Student's $t$ test or one-way
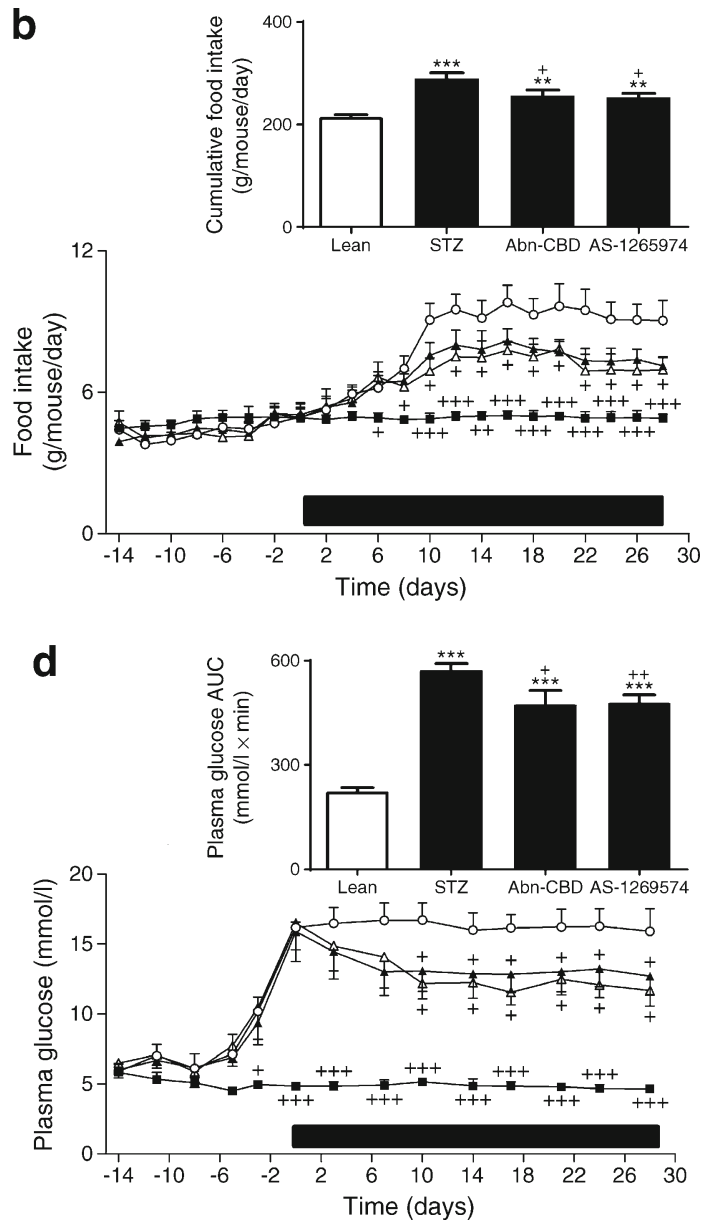

induced diabetic mice treated with saline vehicle; black triangles, diabetic mice treated with Abn-CBD; white triangles, diabetic mice treated with AS-1269574. Values are means \pm SEM for six mice. $* p<0.05, * * p<0.01$ and $* * * p<0.001$ compared with normal mice; ${ }^{+} p<0.05,{ }^{++} p<0.01$ and ${ }^{+++} p<0.001$ compared with diabetic mice 


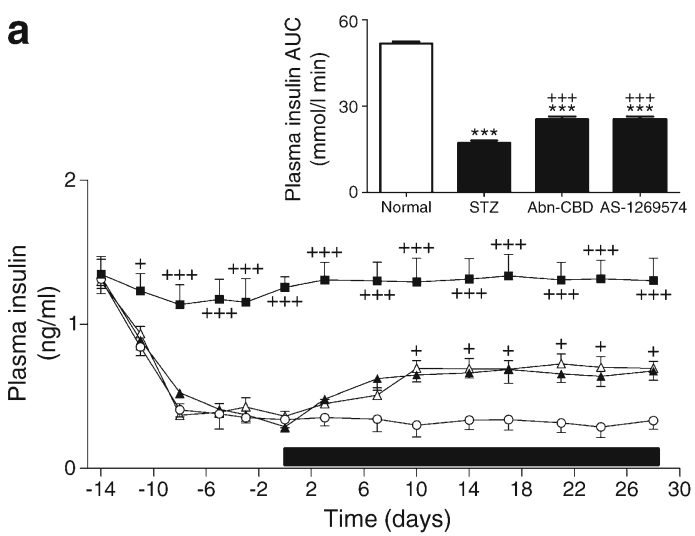

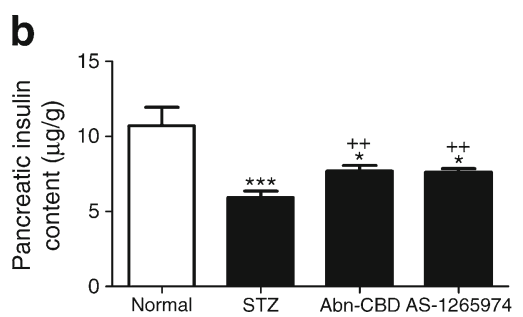

C

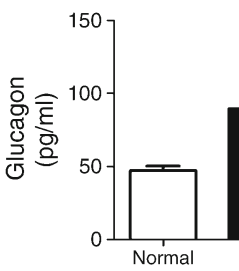

Fig. 2 Effect of daily administration of Abn-CBD and AS-1269574 on non-fasting plasma insulin (a), pancreatic insulin content (b), plasma glucagon (c) and GLP-1 (d) in STZ-induced diabetic mice. In (a) variables were measured before and during 28 days of treatment with Abn-CBD, AS-1269574 or saline vehicle (treatment period indicated by the horizontal black bar) and in (b-d) they were measured after 28 days of d

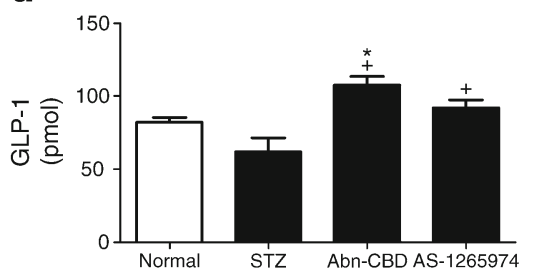

treatment. Black squares, non-diabetic mice treated with saline (normal); white circles, STZ-induced diabetic mice treated with saline vehicle; black triangles, diabetic mice treated with Abn-CBD; white triangles, diabetic mice treated with AS-1269574. Values are means \pm SEM for six mice. $* p<0.05, * * p<0.01$ and $* * * p<0.001$ compared with normal mice ${ }^{+} p<0.05,{ }^{++} p<0.01$ and ${ }^{+++} p<0.001$ compared with diabetic mice
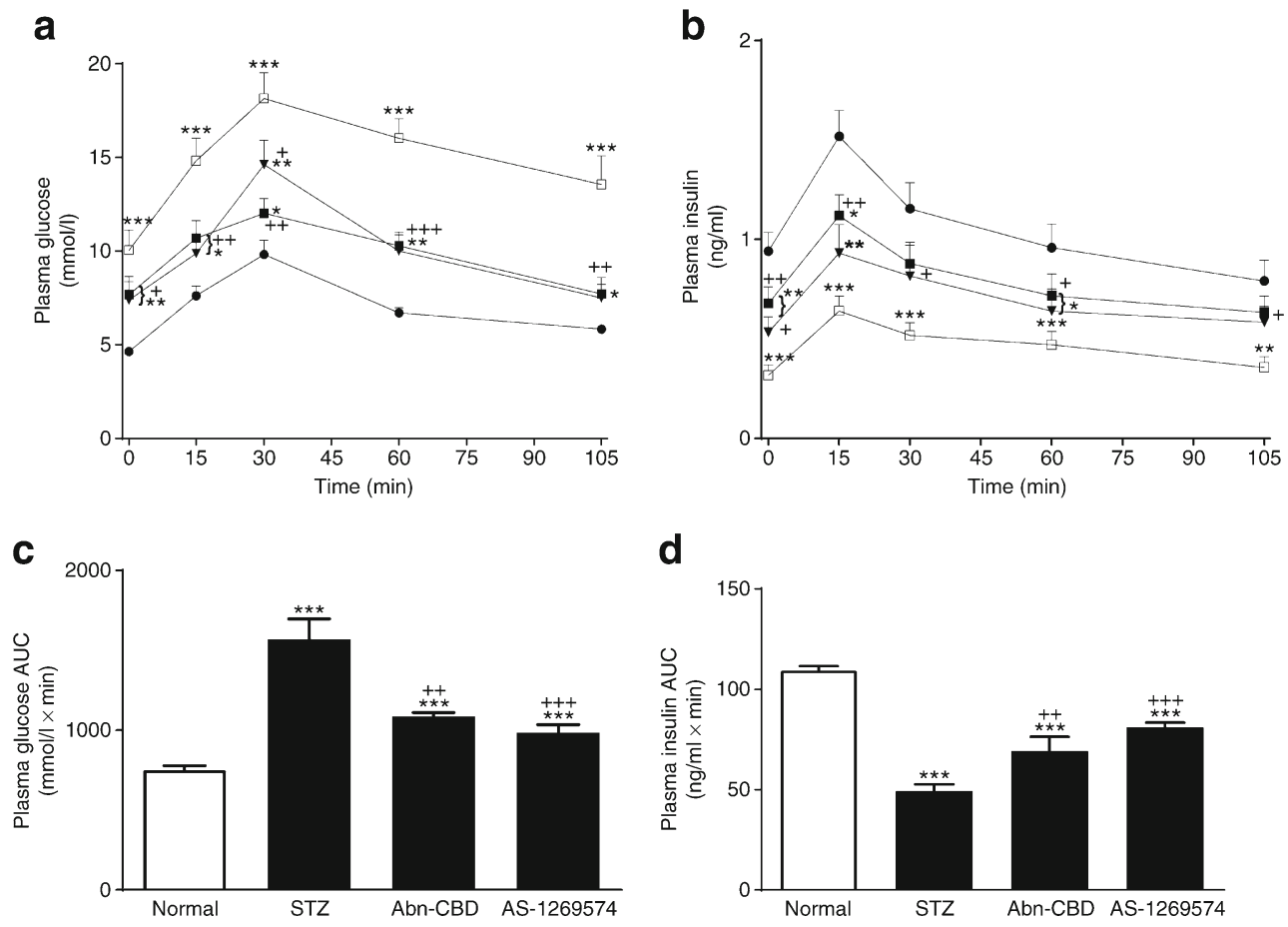

d

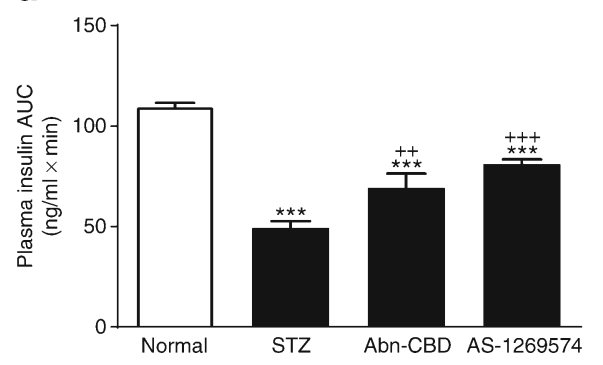

Fig. 3 (a, b) Effect of daily administration of Abn-CBD and AS-1269574 on glucose tolerance (a) and plasma insulin response to glucose (b) in STZ-induced diabetic mice fasted for $18 \mathrm{~h}$. OGTT (18 mmol/[kg body weight]) was conducted 28 days after treatment with Abn-CBD, AS-1269574 or saline vehicle. (c, d) Plasma glucose (c) and insulin (d) AUC values for 0-105 min post injection are shown. Black

circles, non-diabetic mice treated with saline (normal); white squares, STZ-induced diabetic mice treated with saline vehicle; black triangles, diabetic mice treated with Abn-CBD; black squares, diabetic mice treated with AS-1269574. Values are means \pm SEM for six mice. $* p<0.05$, $* * p<0.01$ and $* * * p<0.001$ compared with normal mice; ${ }^{+} p<0.05$, ${ }^{++} p<0.01$ and ${ }^{+++} p<0.001$ compared with diabetic mice 
ANOVA on Prism graph pad version 5.0. Differences in data were considered to be statistically significant for $p<0.05$.

\section{Results}

Effect of Abn-CBD and AS-1269574 on food intake, fluid intake, body weight, non-fasting plasma glucose, insulin, glucagon and pancreatic insulin content Multiple-low-dose STZ lowered body weight by $10 \%(p<0.05)$ (Fig. 1a). Administration of the GPCR agonists Abn-CBD and AS1269574 over 28 days had no effect on body weight. Food intake was decreased by $21-23 \%$ by Abn-CBD $(p<0.05)$ and AS-1265974 $(p<0.05)$ (Fig. 1b). Non-fasting plasma glucose was improved by Abn-CBD $(20 \%, p<0.05)$ and AS-1269574 $(26 \%, p<0.05)$ (Fig. 1d) while polydipsia was decreased by $33-35 \%$ with Abn-CBD $(p<0.01)$ and AS-1269574 $(p<0.01)$ (Fig. 1c). Non-fasting plasma insulin was increased by Abn-CBD (47\%, $p<0.05)$ and AS-1269574 (48\%, $p<0.05$ ) by $10-28$ days (Fig. 2 a). This was associated with increased pancreatic insulin content in both groups treated with synthetic agonists $(p<0.01)$ (Fig. 2b). Plasma glucagon was decreased $(p<0.05$ or $p<0.01)$ and GLP-1 was increased $(p<0.05)$ in non-fasting terminal plasma by both Abn-CBD and AS-1269574, compared with measurements in STZ-treated control mice (Fig. 2c, d).

Effect of Abn-CBD and AS-1269574 on oral glucose tolerance and insulin sensitivity Daily oral administration of GPCR agonists for 28 days decreased the glycaemic excursion during an OGTT by 19-44\% (Abn-CBD, $p<0.05$ or $p<0.001)$ and $23-43 \%$ (AS-1269574, $p<0.05$ or $p<0.001)$ compared with the control STZ group (Fig. 3a, c). In addition, Abn-CBD and AS-1269574 augmented glucose-stimulated insulin by $27-40 \%(p<0.05$ or $p<0.01)$ and $35-53 \%$ $(p<0.05$ or $p<0.01)$, respectively (Fig. 3b, d). Plasma glucose concentrations and AUC values following injection of exogenous insulin were also reduced by Abn-CBD $(p<0.05)$ and AS-1269574 $(p<0.01)$ after 28 days of treatment (Fig. 4).

Effect of Abn-CBD and AS-1269574 on dual-energy x-ray absorption measurements and non-fasting plasma lipid profile Dual-energy $x$-ray absorption (DEXA) scanning revealed a decreased body mass in the three groups of STZ-treated mice $(p<0.05)$ (Fig. 5a), with no effects on body fat expressed as percentage of body mass (Fig. 5b). AS-1269574 and Abn-CBD had no effect on body weight or fat content, compared with STZ-treated controls (Fig. 5a, b). GPR119 agonist AS-1269574 enhanced both bone mineral density $(6 \%, p<0.05)$ and bone mineral content $(13 \%$, $p<0.05)$, while GPR55 agonist Abn-CBD augmented bone mineral content $(14 \%, p<0.05)$ (Fig. 5 c, d). After 28 days of treatment, non-fasting triacylglycerols decreased by $19 \%$ with
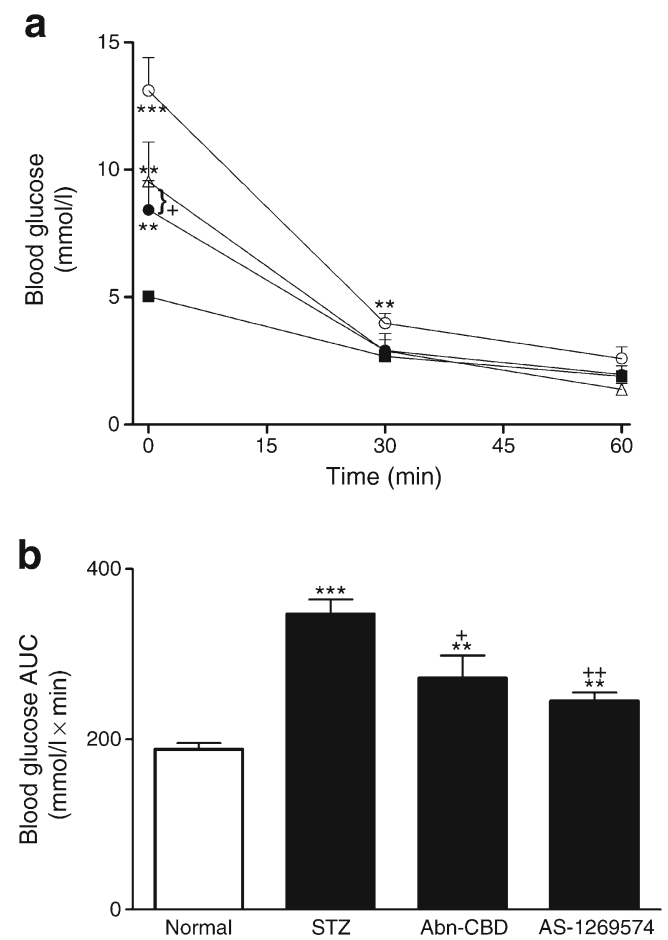

Fig. 4 Effect of daily administration of Abn-CBD and AS-1269574 on insulin sensitivity depicted in terms of glucose (a) and AUC for glucose values (b) in STZ-induced diabetic mice. Insulin sensitivity tests (25 U/ [kg body weight]) were conducted after 28 days of treatment with AbnCBD and AS-1269574 or saline vehicle. Black squares, non-diabetic mice treated with saline (normal); white circles, STZ-induced diabetic mice treated with saline; white triangles, diabetic mice treated with Abn-CBD; black circles, diabetic mice treated with AS-1269574. Values are means \pm SEM for six mice. $* * p<0.01$ and $* * * p<0.001$ compared with normal mice; ${ }^{+} p<0.05$ and ${ }^{++} p<0.01$ compared with diabetic mice

Abn-CBD $(p<0.05)$ and 32\% with AS-1269574 $(p<0.01)$ compared with diabetic controls (Fig. 6a). Similarly, total cholesterol was reduced by both Abn-CBD $(17 \%, p<0.01)$ and AS-1269574 (15\%,p<0.05) (Fig. 6b), while AS-1269574 augmented HDL-cholesterol concentrations by $19 \%(p<0.01)$ when compared to the lean group (Fig. 6c).

Effect of Abn-CBD and AS-1269574 on islet morphology Multiple-low-dose STZ-induced diabetes was associated with diminished insulin-positive beta cells ( $p<0.001$; Fig. 7a, f), augmented glucagon-positive alpha cells $(p<0.001$; Fig. 7b, g) and decreased GPR119 expression $(p<0.001$; Fig. 7d, h). These islet abnormalities were partially reversed in Abn-CBD- and AS-1269574 treated groups, with increased insulin-positive beta cells ( $p<0.001$; Fig. 7a, f) and reduced glucagon expression in alpha cells $(p<0.01$ or $p<0.001$; Fig. 7b, g) when comparing the Abn-CBD- and AS-1269574-treated mice with saline-treated STZ-induced diabetic mice. Additionally, administration of Abn-CBD enhanced GPR55 islet expression ( $p<0.001$; Fig. 7c, h) while 
Fig. 5 Effect of daily administration of Abn-CBD and AS-1269574 on total body mass (a), fat (b), bone mineral density (c) and bone mineral content (d) as measured by DEXA scanning in STZ-induced diabetic mice. Variables were measured after 28 days of treatment with AbnCBD, AS- 1269574 or saline vehicle. Values are means \pm SEM for six mice. $* p<0.05$ compared with non-diabetic mice treated with saline; ${ }^{+} p<0.05$ compared with diabetic mice a

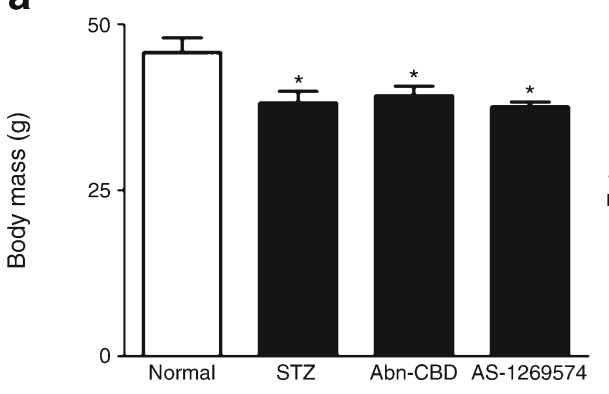

b

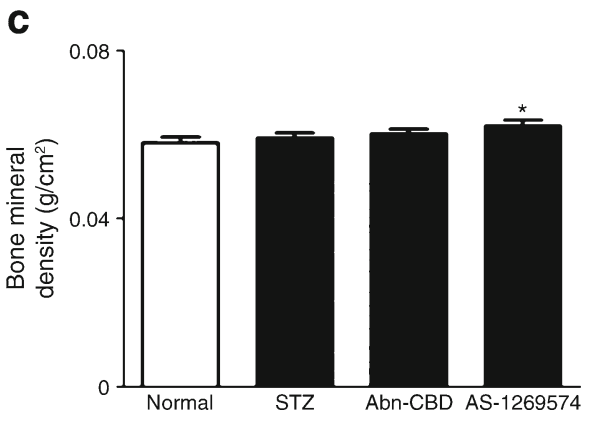

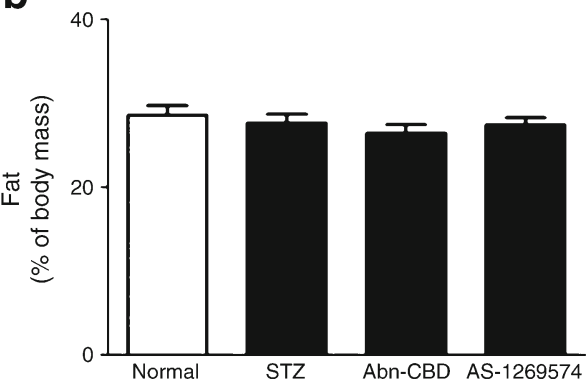

d

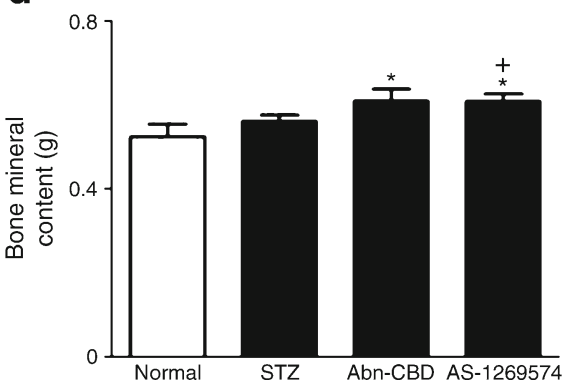

AS-1269574 increased GPR119 expression $(p<0.001$; Fig. 7d, h), compared with saline-treated STZ controls.

To investigate beta cell proliferation with GPR119 and GPR55 agonists, Ki-67 was used as a nuclear marker for cellular replication (Fig. 8). Both Abn-CBD and AS-1269574 enhanced the percentage of insulin/Ki-67 co-positive cells (Fig. 8k-1). Non-diabetic mice treated with saline $(0.4 \%)$ and untreated STZ-induced diabetic $(0.6 \%)$ mice exhibited minimal beta cell proliferation while insulin/Ki-67 positive cell counts were significantly enhanced in Abn-CBD $(1.8 \%$, $p<0.001)$ and AS-1269574 (2.3\%, $p<0.001)$ treatment groups (Fig. 8m).

Acute effect of Abn-CBD and AS-1269574 in wild-type C57BL/6 mice and in Gipr- and Glp1r-knockout mice Administration of GIP or GLP-1 had no biological effects
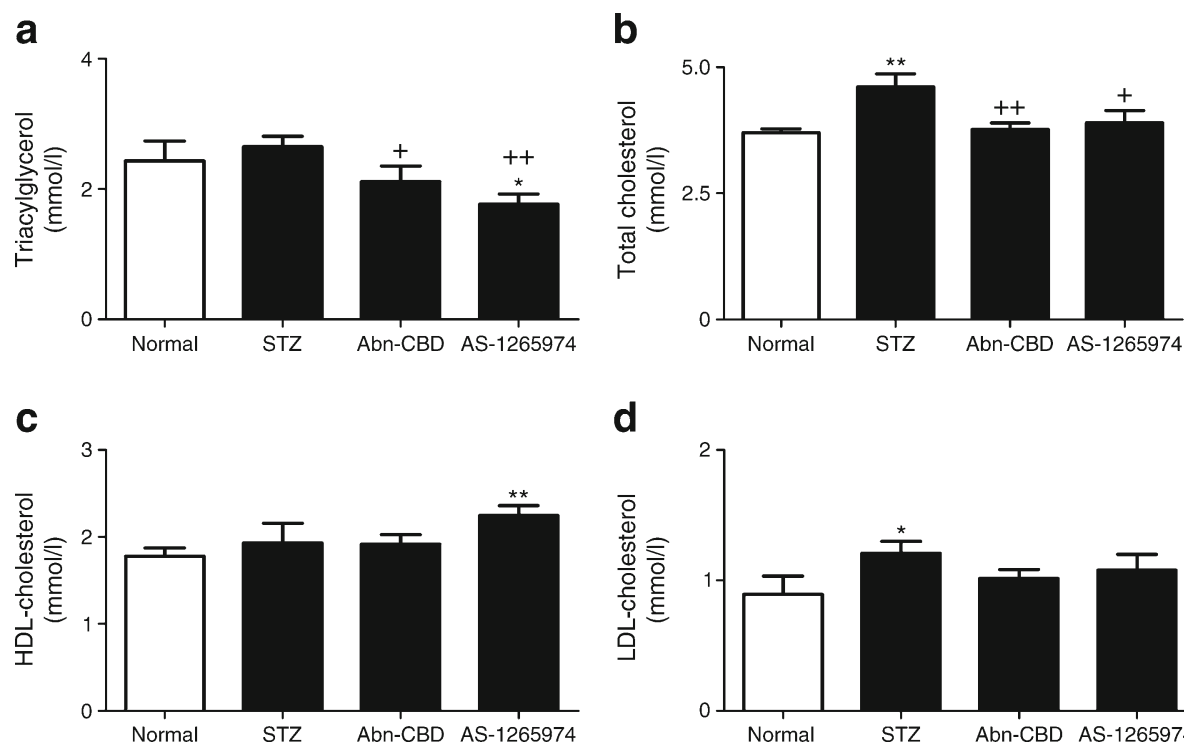

d

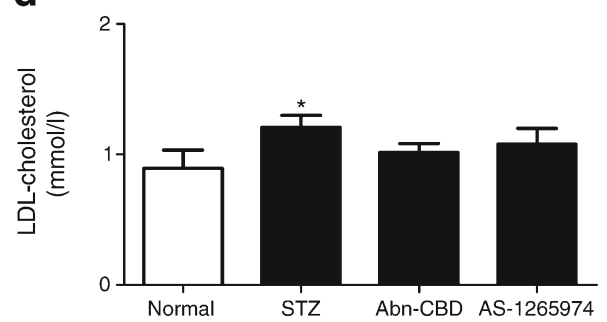

Fig. 6 Effect of daily administration of Abn-CBD and AS-1269574 on plasma triacylglycerols (a), total cholesterol (b), HDL-cholesterol (c) and LDL-cholesterol (d) in STZ-induced diabetic mice. LDL-cholesterol was calculated using the Friedewald equation (LDL-cholesterol $=$ total cholesterol minus HDL-cholesterol minus [triacylglycerols/2.2]). Variables

were measured after 28 days of treatment with Abn-CBD, AS-1269574 or saline vehicle. Values are means \pm SEM for six mice. ${ }^{*} p<0.05$ and ${ }^{* *} p<0.01$ compared with non-diabetic mice treated with saline; ${ }^{+} p<0.05$ and ${ }^{++} p<0.01$ compared with diabetic mice 

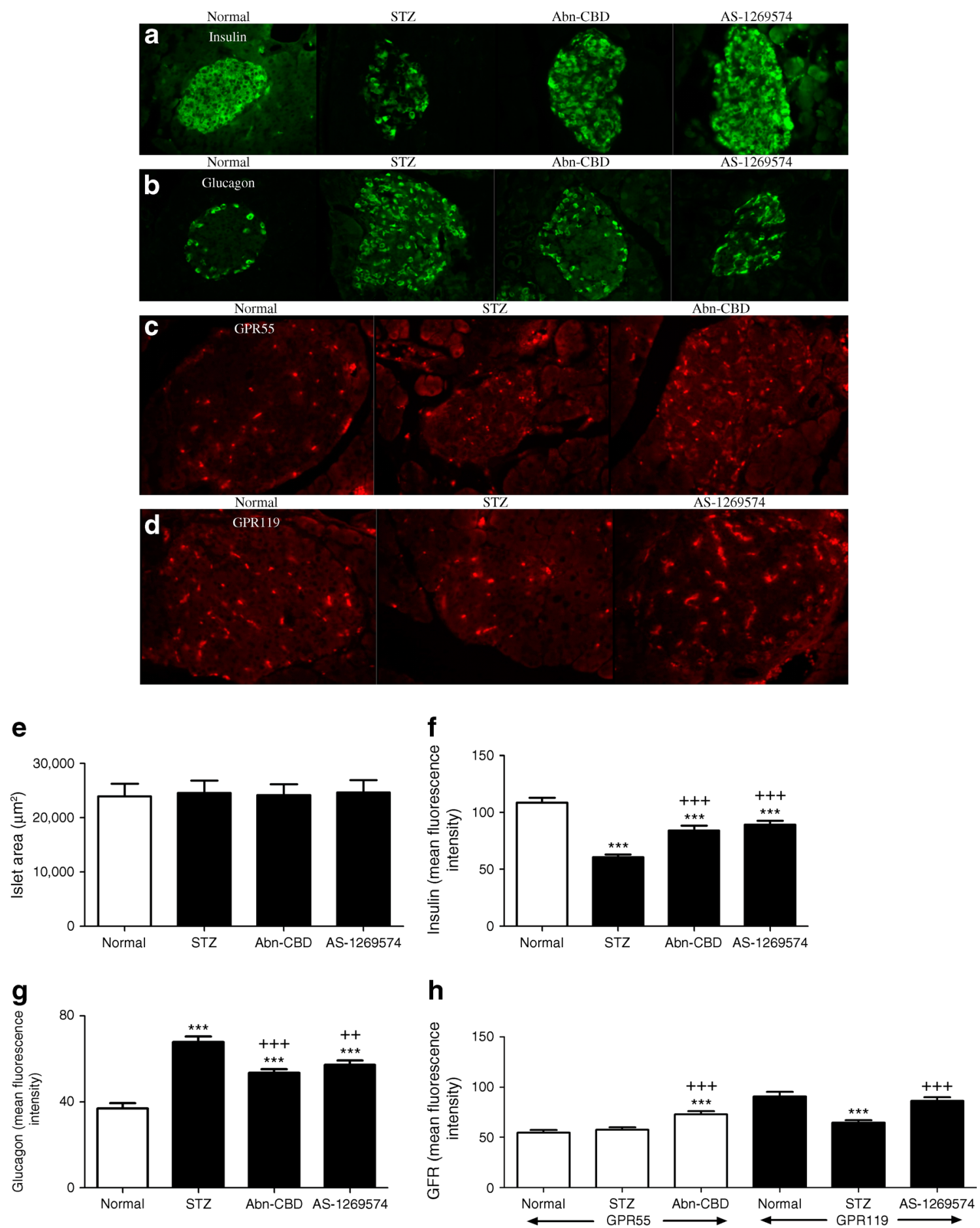

Fig. 7 (a-d) Representative images of immunocytochemical staining for insulin (a), glucagon (b), GPR55 (c) and GPR119 (d) in the pancreas of STZ-induced diabetic mice after 28 days of treatment with Abn-CBD, AS-1269574 or saline vehicle. Magnification $\times 40$. (e-h) Islet area (e) and relative fluorescence for insulin (f), glucagon (g), GPR55 and GPR119

in either Gipr-knockout mice or Glp $1 r$-knockout mice, respectively (Fig. 9b, c, e and f). In contrast, in C57BL/6 mice GIP lowered plasma glucose by $18-24 \%(p<0.05$ or $p<0.01)$ and enhanced glucose-stimulated insulin release (h) determined using cell $\mathrm{F}$ software. Values are means \pm SEM for six mice, 25 islets per group. $* * * p<0.001$ compared with non-diabetic mice treated with saline; ${ }^{++} p<0.01$ and ${ }^{++} p<0.001$ compared with diabetic mice

by $26-29 \%(p<0.05)$ (Fig. 9a, d). Similarly, GLP-1 attenuated glucose levels by $23-32 \%(p<0.05$ or $p<0.001)$ and stimulated insulinotropic ability by $33-40 \%(p<0.01)$ in wild-type controls (Fig. 9a, d). In these control mice, 
Fig. 8 Immunocytochemical staining for insulin and $\mathrm{Ki}-67$ in the pancreas of STZ-induced diabetic mice after 28 days of treatment with Abn-CBD, AS1269574 or saline vehicle. (a-I) Representative images are shown for insulin (a-d), Ki-67 (e-h) and merged insulin and Ki-67 (i-l) Magnification $\times 40$. $(\mathbf{m})$

Percentage of Ki-67-positive beta cells. Values are means \pm SEM for six mice, 25 islets per group.

$* * * p<0.001$ compared with nondiabetic mice treated with saline; ${ }^{+++} p<0.001$ compared with diabetic mice. Arrows indicate insulin/Ki-67 co-positive beta cells
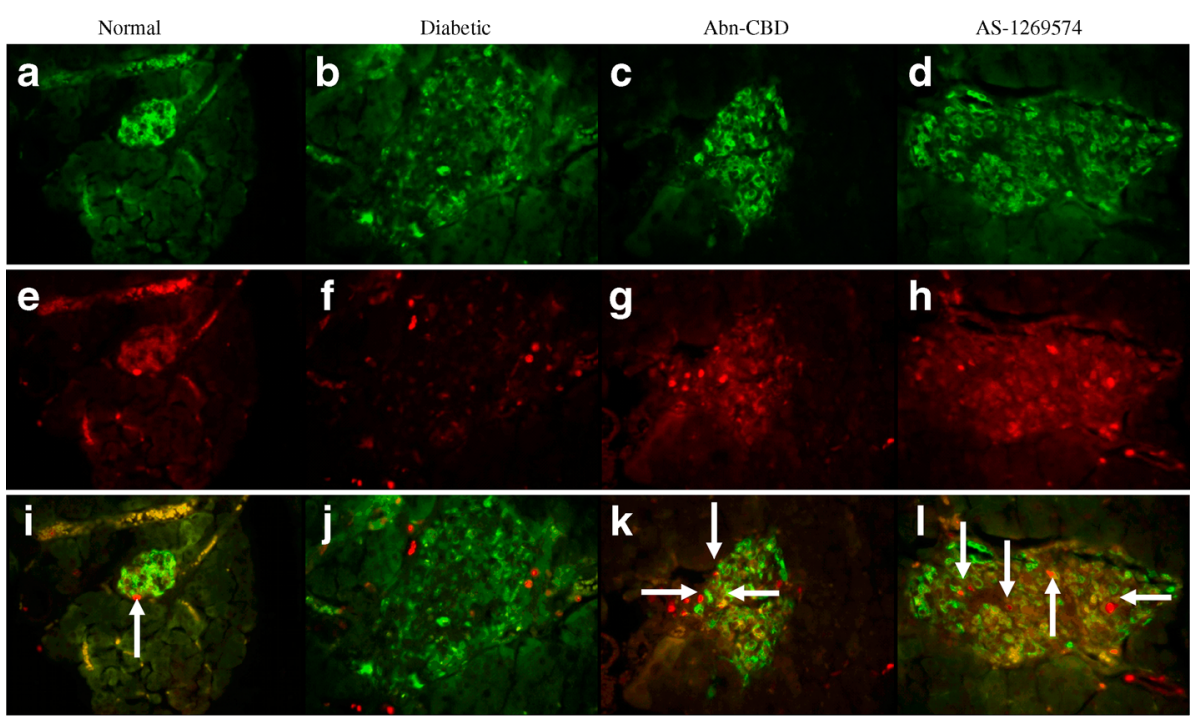

m

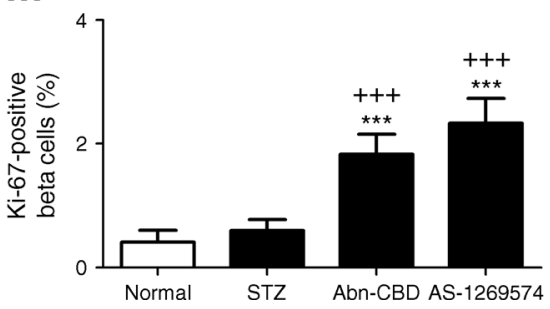

\section{Discussion}

Much interest has been focused recently on fatty acid GPCRs in relation to their potential beneficial effects on glucose homeostasis in type 2 diabetes and other obesity-related diseases $[1-3,26]$. Several novel fatty acid receptors, including GPR55 and GPR119, have shown promise as emerging targets of diabetes therapies. Previous research has highlighted the potent acute glucose-lowering and insulinotropic ability of the GPCR agonists Abn-CBD and AS-1269574 [9, 21] and our acute in vivo studies, using GPR55 and GPR119 antagonists, have confirmed the specificity of Abn-CBD and AS-1269574 in islets.

The present study evaluated the glucose-lowering and insulinotropic properties of small-molecule agonists Abn-CBD and AS-1269574 in multiple-low-dose STZ-induced diabetes in mice. This is a commonly employed means of inducing diabetes [27, 28], which in the present study was associated with decreased body weight, hyperphagia, polydipsia, moderate hyperglycaemia, hyperglucagonaemia and hypoinsulinaemia but with good numbers of surviving functional beta cells, representing a model of mild type 1 diabetes. Daily oral administration of Abn-CBD and AS-1269574 lowered plasma glucose, plasma glucagon and food and fluid intake. In harmony with this, plasma insulin and pancreatic insulin content were increased in both treatment groups. Following long-term administration 

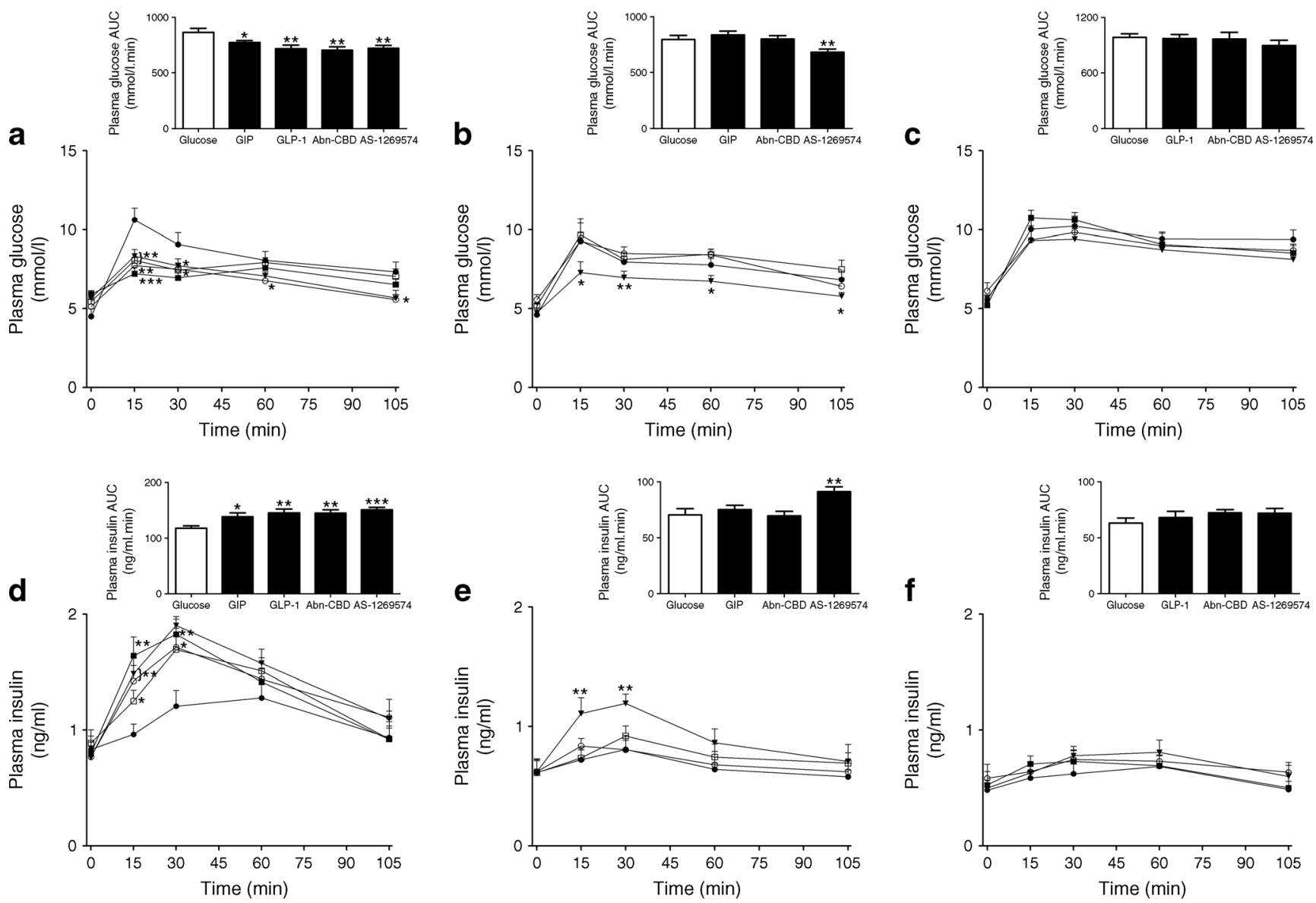

Fig. 9 Acute effect of Abn-CBD and AS-1269574 on glucose tolerance, and the plasma insulin response to oral glucose in C57BL/6 wild-type mice (a, d) and in C57BL/6 mice with knockout of Gip (b, e) or Glp1 receptors $(\mathbf{c}, \mathbf{f})$. Plasma glucose $(\mathbf{a}-\mathbf{c})$ and insulin $(\mathbf{d}-\mathbf{f})$ were determined before and after oral administration of glucose $(18 \mathrm{mmol} /[\mathrm{kg}$ body weight]) alone or in combination with Abn-CBD or AS-1269574

$(0.1 \mu \mathrm{mol} /[\mathrm{kg}$ body weight $])$. Black circles, glucose; white squares, glucose + GIP (25 nmol 1-1 $\left.\mathrm{kg}^{-1}\right)$; black squares, glucose + GLP-1 $\left(25 \mathrm{nmol} \mathrm{l} \mathrm{l}^{-1} \mathrm{~kg}^{-1}\right)$; white circles, glucose + Abn-CBD $\left(0.1 \mu \mathrm{mol} \mathrm{l}{ }^{-1}\right.$ $\left.\mathrm{kg}^{-1}\right)$; black triangles, glucose + AS-1269574 (0.1 $\left.\mu \mathrm{mol} \mathrm{l}^{-1} \mathrm{~kg}^{-1}\right)$. Values are means \pm SEM for six mice. $* p<0.05$, $* * p<0.01$ and $* * * p<0.001$ compared with $18 \mathrm{mmol} / \mathrm{l}$ glucose

of the agonists, glucose tolerance and insulin sensitivity were markedly improved. Additionally, total cholesterol and triacylglycerols were decreased by Abn-CBD and AS-1269574 and HDL-cholesterol was augmented by AS-1269574. Interestingly, our data would suggest a link between GPCR activation and suppression of hyperphagia. We found that GPR55 and GPR119 agonists decreased food consumption and appetite, though we observed no effect on overall body weight. This is in contrast to some published literature suggesting a link between GPR55 antagonism and reduced food consumption and body weight gain [22]. The accompanying decrease in fluid intake in the mice in our study most likely reflects the improved hyperglycaemic status following treatment with the two GPCR agonists. Moreover, GPR55 expression has been found to be increased in adipose tissue of obese individuals and further so in obese patients with type 2 diabetes, with GPR55 expression correlating with body weight, BMI and percentage fat mass [29]. Ex vivo studies using both adipose tissue explants and differentiated primary adipocytes show that L- $\alpha$-lysophosphatidylinositol, an endogenous GPR55 agonist, increased the expression of genes stimulating fat deposition in adipose tissue and in differentiated adipocytes from visceral fat of obese patients it raised intracellular $\mathrm{Ca}^{2+}$ concentration. The GPR119 data is generally consistent with a recent study which found that AS-1907417, a modified form of AS-1269574, improved lipid profile, plasma insulin, plasma glucose and pancreatic insulin content over a 4 week treatment period in $d b / d b$ mice [30]. These recent studies suggest that activation of GPR55 and GPR119 could play a role in weight management, energy load and lipid metabolism.

Very few previous studies have assessed long-term administration of AS-1269574 and Abn-CBD in animal models of diabetes. Interestingly, bone mineral content, assessed by DEXA, was increased by agonising GPR119 with AS-1269574. GPR55 is expressed on osteoclasts [20] and, in contrast to our observations, GPR55-receptor-knockout mice have been reported to exhibit enhanced quantity and 
Fig. 10 Acute effect of GPR119 agonist in combination with GPR119 antagonist exendin (9-

39) on plasma glucose (a, c) and plasma insulin $(\mathbf{b}, \mathbf{d})$. Fasted male lean NIH Swiss mice $(n=6)$ received glucose $(18 \mathrm{mmol} /[\mathrm{kg}$ body weight]) alone or in combination with GPR119 agonist AS1269754 and/or GPR119 antagonist exendin (939) $(0.1 \mu \mathrm{mol} /[\mathrm{kg}$ body weight $])$. Values are means \pm SEM. Black circles, glucose alone; white squares, glucose + AS-1269574; black triangles, glucose + exendin (9-39); black squares, glucose + AS-1269574 + exendin (9-39). $* p<0.05, * * p<0.01$ and $* * * p<0.001$ compared with glucose $;{ }^{+} p<0.05,{ }^{++} p<0.01$ and ${ }^{+++} p<0.001$ compared with glucose + AS-1269574 a

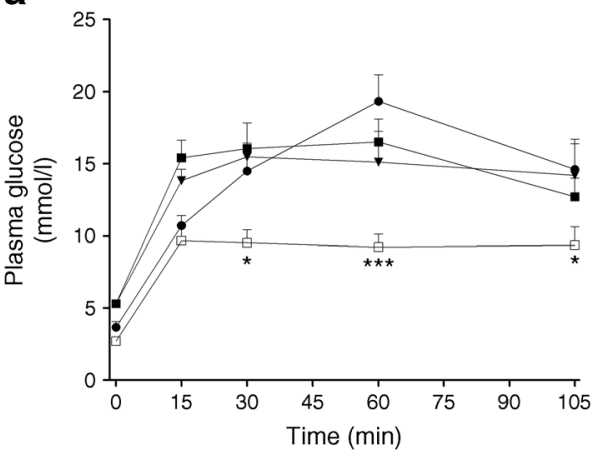

C

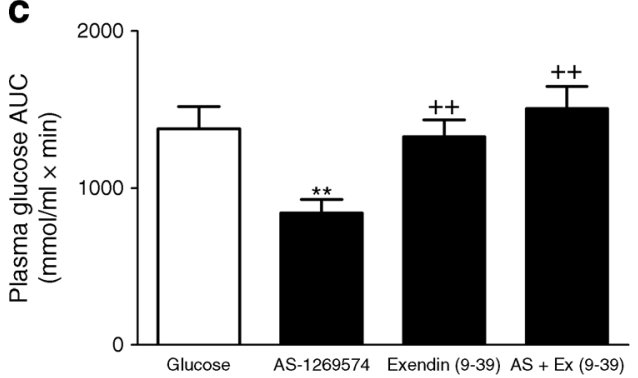

b

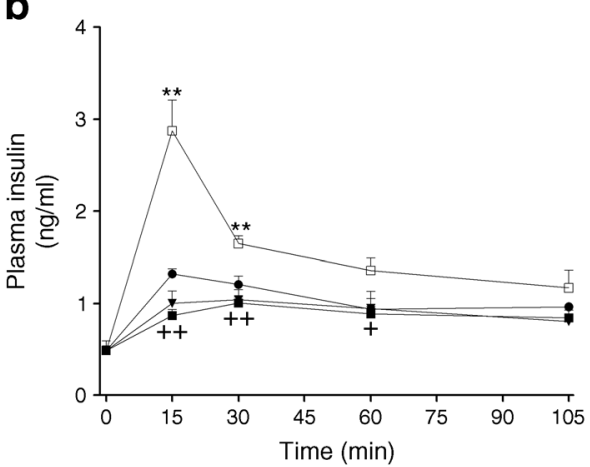

d

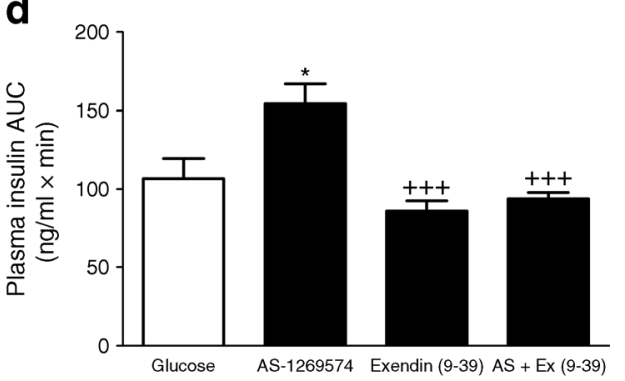

thickness of trabecular bone [20]. This difference may reflect an adaptive response in mice deficient in GPR55. No data are currently available on GPR119 and bone metabolism. Of interest, recent studies have highlighted the importance of GIP [31] and GLP-1 receptors [32] in bone physiology, including bone strength and quality. This may explain the enhancement in bone mineral density and content by the GPCR agonists in this study as the receptors, in particular GPR119, has been implicated in GIP and GLP-1 secretion [6, 33, 34].
In the present study, multiple-low-dose STZ induced a relatively moderate form of diabetes associated with hypoinsulinaemia and mild effects on islet architecture. The islets contained good numbers of surviving positively stained insulin beta cells, increased numbers of glucagon-secreting alpha cells and decreased expression of the GPR119 receptor. Oral administration of Abn-CBD or AS-1269574 resulted in increased numbers of insulin-secreting beta cells and reduced hyperglucagonemia confirmed by decreased circulating
Fig. 11 Acute effect of GPR55 agonist in combination with GPR55 antagonist CBD on plasma glucose $(\mathbf{a}, \mathbf{c})$ and plasma insulin $(\mathbf{b}, \mathbf{d})$. Fasted male lean $\mathrm{NIH}$ Swiss mice $(n=6)$ received glucose $(18 \mathrm{mmol} /[\mathrm{kg}$ body weight]) alone or in combination with GPR55 agonist Abn-CBD and/or GPR55 antagonist CBD. Black circles, glucose alone; white squares, glucose + AbnCBD; black triangles, glucose + CBD; black squares, glucose + Abn-CBD + CBD. Values are means \pm SEM. $* * p<0.01$ and $* * * p<0.001$ compared with glucose $;{ }^{++} p<0.01$ and ${ }^{+++} p<0.001$ compared with glucose + Abn-CBD a

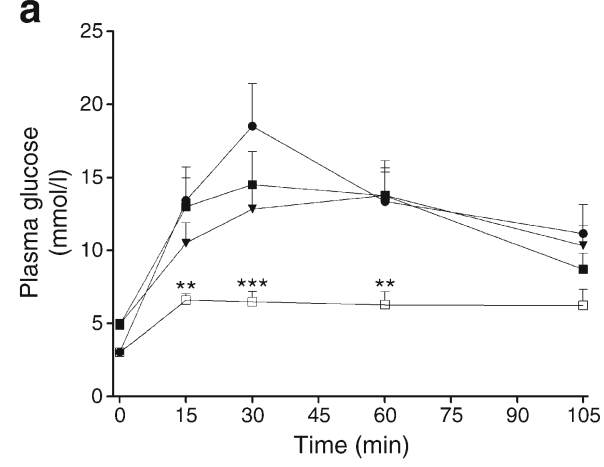

C

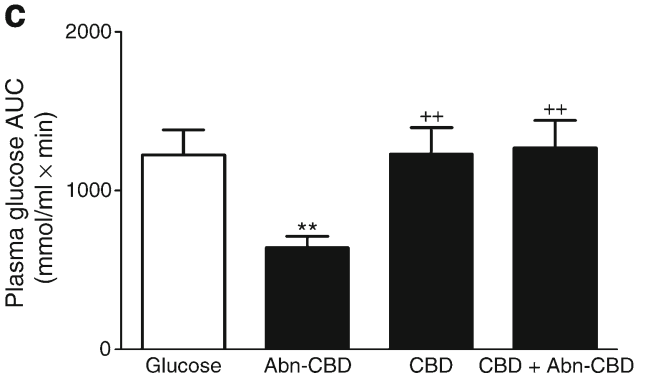

b

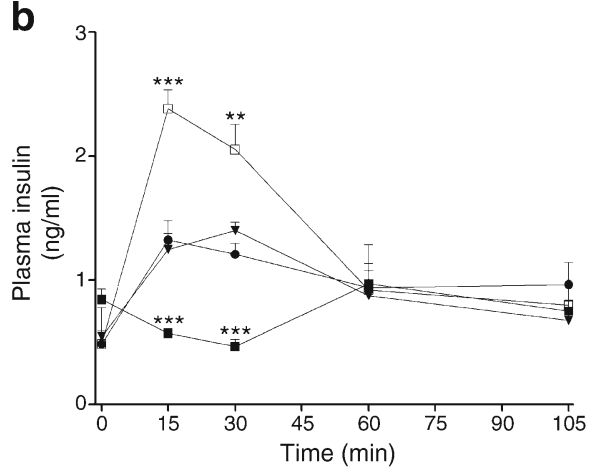

d

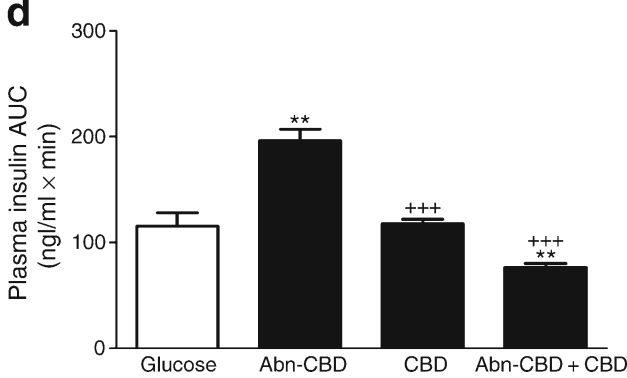


plasma glucagon levels. The expression of GPR55 and GPR119 was enhanced by Abn-CBD and AS-1269574, respectively, with GPR119 reverting to normal expression levels. In addition, treatment with GPR55 and GPR119 agonists augmented beta cell proliferation and regeneration. Consistent with this, a recent study reported that the GPR119 agonist PSN-632408 increased GLP-1 secretion and beta cell proliferation as assessed by $\mathrm{Ki}-67$ and $\mathrm{BrdU}$ staining; these effects were further augmented by DPP-IV inhibitor sitagliptin [14]. Many factors are known to play a role in the regulation of beta cell proliferation, including incretins, and further studies are required to investigate the possibility of parallel changes in apoptosis and to discover whether the increased cellular proliferation and replication observed in this study with long-term administration of GPCR agonists is a result of the action of incretins on beta cell proliferation and beta cell function. Both GIP and GLP-1 have been implicated in a number of protective functions in pancreatic beta cells including proliferation, neogenesis and anti-apoptosis [35].

This study has confirmed $[6,33,34]$ that GPR119 agonists stimulate the release of GLP-1 from L cells. The GPR55 agonist Abn-CBD exhibited potent glucose-lowering and insulin-releasing properties in C57BL/6 wild-type mice, effects that were abolished in both Gipr-and Glp1r-knockout mice. The GPR119 agonist AS-1269574 displayed strong glucose-lowering and insulinotropic ability in wild-type C57BL/6 mice as well as Gipr-knockout mice. In contrast, GPR119 activation with AS-1269574 removed the glucose-lowering effect of the ligand in Glp1r-knockout mice. These data indicate that, in addition to direct stimulatory effects of the agonists on beta cells, the beneficial effects of Abn-CBD also involve the GIP and GLP-1 receptors and AS-1269574 activation of the GLP-1 receptor.

Overall these results indicate that GPCR small-molecule agonists Abn-CBD and AS-1269574 exert a broad spectrum of actions on glucose homeostasis, islet and enteroendocrine cells, lipid profiles and pancreatic and bone composition. Interestingly, few studies have assessed the role of GPR55 in diabetes $[16,18]$, with no literature probing the involvement of incretin hormones in the mechanism of action of GPR55. In contrast, several studies have identified the importance of GLP-1 [11, 12, 14, 15] and GIP [6] in GPR119 activation in glucose homeostasis. Similar to the findings of this study, the GPR119 agonist AS-1269574 has also been found to enhance plasma GLP-1 concentrations [11, 34]. Few studies have assessed the role of GPR119 in GIP signalling and the exact molecular mechanisms remain unclear. The synthetic agonist AR-231453 enhanced both GIP and GLP-1 levels in wild-type mice but not in Gpr119-knockout mice [34]. Additionally, AR-231453 stimulated GIP and GLP-1 release in wild-type mice and Glp1r- and Gipr-knockout mice [6]. Further studies are clearly warranted to assess the role of GPR119 and GPR55 agonists on the incretin pathway.
In conclusion, long-term administration of GPR55 agonist Abn-CBD and GPR119 agonist AS-1269574 improved glycaemic control in a multiple-low-dose STZ-induced mouse model of diabetes, resulting in decreased plasma glucose and glucagon and improved plasma insulin, GLP-1 and lipid profiles. Additionally, glucose tolerance and insulin sensitivity were enhanced, with positive actions on the pancreas and bone. The results also indicate an important action through the incretin pathway, suggesting that agonists capable of agonising both fatty acid GPCRs and incretin secretion may have therapeutic potential in the future.

Funding These studies were supported by the Department of Education and Learning, Northern Ireland, and Ulster University Strategic Funding.

Contribution statement All authors made substantial contributions to conception and design, acquisition of data, reviewed the literature, drafted and revised the manuscript and approved the final submitted manuscript. $\mathrm{AMK}$ is the guarantor of this work.

Duality of interest The authors declare that there is no duality of interest associated with this manuscript.

Open Access This article is distributed under the terms of the Creative Commons Attribution 4.0 International License (http:// creativecommons.org/licenses/by/4.0/), which permits unrestricted use, distribution, and reproduction in any medium, provided you give appropriate credit to the original author(s) and the source, provide a link to the Creative Commons license, and indicate if changes were made.

\section{References}

1. Rayasam GV, Tulasi VK, Davis JA, Bansal VS (2007) Fatty acid receptors as new therapeutic targets for diabetes. Expert Opin Ther Targets 11:661-671

2. Yonezawa T, Kurata R, Yoshida K, Murayama MA, Cui X, Hasegawa A (2013) Free fatty acids-sensing G protein-coupled receptors in drug targeting and therapeutics. Curr Med Chem 20: 3855-3871

3. Moran BM, Flatt PR, McKillop AM (2016) G protein-coupled receptors: signalling and regulation by lipid agonists for improved glucose homoeostasis. Acta Diabetol 53:177-188

4. Vangaveti V, Shashidhar V, Jarrod G, Baune BT, Kennedy RL (2010) Free fatty acid receptors: emerging targets for treatment of diabetes and its complications. Ther Adv Endocrinol Metab $1: 165-175$

5. Godlewski G, Offertaler L, Wagner JA, Kunos G (2009) Receptors for acylethanolamides- GPR55 and GPR119. Prostaglandins Other Lipid Mediat 89:105-111

6. Flock G, Holland D, Seino Y, Drucker DJ (2011) GPR119 regulates murine glucose homeostasis through incretin receptor-dependent and independent mechanisms. Endocrinology 152:374-383

7. Drucker DJ (2006) The biology of incretin hormones. Cell Metab 3: 153-165

8. Sandoval DA, D Alessio DA (2015) Physiology of proglucagon peptides: role of glucagon and GLP-1 in health and disease. Physiol Rev 95:513-548 
9. Moran BM, Abdel-Wahab YH, Flatt PR, McKillop AM (2014) Activation of GPR119 by fatty acid agonists augments insulin release from clonal $\beta$-cells and isolated pancreatic islets and improves glucose tolerance in mice. Biol Chem 395:453-464

10. Yoshida S, Ohishi T, Matsui T, Shibasaki M (2010) Identification of a novel GPR119 agonist, AS1269574, with in vitro and in vivo glucose-stimulated insulin secretion. Biochem Biophys Res Commun 400:437-441

11. Chepurny OG, Bertinetti D, Diskar M et al (2013) Stimulation of proglucagon gene expression by human GPR119 in enterendocrine L-cell line GLUTag. Mol Endocrinol 27:1267-1282

12. Gao J, Tian L, Weng G et al (2011) Stimulating beta cell replication and improving islet graft function by GPR119 agonists. Transpl Int 24:1124-1134

13. Lauffer LM, Iakoubov R, Brubaker PL (2009) GPR119 is essential for oleoylethanolamide-induced glucagon-like peptide-1 secretion from the intestinal enteroendocrine L-cells. Diabetes 58:1058-1066

14. Ansarullah LY, Holstein M, DeRuyter B, Rabinovitch A, Guo Z (2013) Stimulating $\beta$-cell regeneration by combining a GPR119 agonist with a DPP-IV inhibitor. PLoS One 8:e53345

15. Zhang M, Feng Y, Wang J et al (2013) High throughput screening for GPR119 modulators identifies a novel compound with anti-diabetic efficacy in $d b / d b$ mice. PLoS One 8:e63861

16. Kapur A, Zhao P, Sharir H et al (2009) Atypical responsiveness of the orphan receptor GPR55 to cannabinoid ligands. J Biol Chem 284:29817-29827

17. Romero-Zerbo SY, Rafacho A, Diaz-Arteaga A et al (2011) A role for the putative cannabinoid receptor GPR55 in the islets of Langerhans. J Endocrinol 211:177-185

18. Lin XH, Yuece B, Li YY et al (2011) A novel CB receptor GPR55 and its ligands are involved in regulation of gut movements in rodents. Neurogastroenterol Motil 23:862-871

19. Staton PC, Hatcher JP, Walker DJ et al (2008) The putative cannabinoid receptor GPR55 plays a role in mechanical hyperalgesia associated with inflammatory and neuropathic pain. Pain 139:225-236

20. Whyte LS, Ryberg E, Sims NA et al (2009) The putative cannabinoid receptor GPR55 affects osteoclast function in vitro and bone mass in vivo. Proc Natl Acad Sci U S A 106:16511-16516

21. McKillop AM, Moran BM, Abdel-Wahab YHA, Flatt PR (2013) Evaluation of insulin releasing and antihyperglycaemic activities of GPR55 lipid agonists using clonal beta cells, isolated pancreatic islets and mice. Br J Pharmacol 170:978-990

22. Liu B, Song S, Jones PM, Persaud SJ (2015) GPR55: from orphan to metabolic regulator? Pharmacol Ther 145:35-42
23. Meadows A, Lee JH, Wu CS et al (2016) Deletion of G-proteincoupled receptor 55 promotes obesity by reducing physical activity. Int J Obes (Lond) 40:417-424

24. Kilkenny C, Browne W, Cuthill IC, Emerson M, Altman DG (2010) Animal research: reporting in vivo experiments: the ARRIVE guidelines. Br J Pharmacol 160:1577-1579

25. Flatt PR, Bailey CJ (1981) Abnormal plasma glucose and insulin responses in heterozygous lean $(\mathrm{ob} /+)$ mice. Diabetologia 20: 573-577

26. Moran BM, Abdel-Wahab YH, Vasu S, Flatt PR, McKillop AM (2016) GPR39 receptors and actions of trace metals on pancreatic beta cell function and glucose homoeostasis. Acta Diabetol 53:279-293

27. Ohly P, Dohle C, Abel J, Seissler J, Gleichmann H (2000) Zinc sulphate induces metallothionein in pancreatic islets of mice and protects against diabetes induced by multiple low doses of streptozotocin. Diabetologia 43:1020-1030

28. Ning Y, Zhen W, Fu Z et al (2011) Ranolazine increases $\beta$-cell survival and improves glucose homeostasis in low-dose streptozotocin-induced diabetes in mice. J Pharmacol Exp Ther 337:50-58

29. Moreno-Navarrete JM, Catalán V, Whyte L et al (2012) The L- $\alpha$-lysophosphatidylinositol/GPR55 system and its potential role in human obesity. Diabetes 61:281-291

30. Yoshida S, Tanaka H, Oshima H et al (2010) AS1907417, a novel GPR119 agonist, as an insulinotropic and $\beta$-cell preservative agent for the treatment of type 2 diabetes. Biochem Biophys Res Commun 400:745-751

31. Mieczkowska A, Irwin N, Flatt PR, Chappard D, Mabilleau G (2013) Glucose-dependent insulinotropic polypeptide (GIP) receptor deletion leads to reduced bone strength and quality. Bone 56:337-342

32. Mabilleau G, Mieczkowska A, Irwin N, Flatt PR, Chappard D (2013) Optimal bone mechanical and material properties require a functional GLP-1 receptor. J Endocrinol 219:59-68

33. Chu ZL, Carroll C, Alfonso J et al (2008) A role for intestinal endocrine cell-expressed $\mathrm{G}$ protein-coupled receptor 119 in glycemic control by enhancing glucagon-like peptide- 1 and glucose-dependent insulinotropic peptide release. Endocrinology 149:2038-2047

34. Chepurny OG, Holz GG, Roe MW, Leech CA (2016) GPR119 agonist AS1269574 activates TRPA1 cation channels to stimulate GLP-1 secretion. Mol Endocrinol 30:614-629

35. Garber AJ (2011) Incretin effects on $\beta$-cell function, replication, and mass. Diabetes Care 34:S258-S263 